\title{
Resultados preliminares de la fecundidad y fertilidad del camarón de agua dulce Macrobrachium amazonicum (Heller, 1862)
}

\author{
Preliminary results of the fecundity and fertility of freshwater \\ shrimp Macrobrachium amazonicum (Heller, 1862)
}

\section{Resultados preliminares da fecundidade e fertilidade de água doce camarão Macrobrachium amazonicum (Heller, 1862)}

\section{Elizabeth Aya - Baquero ${ }^{1 *}$, Katerine Betancourt ${ }^{1 *}$}

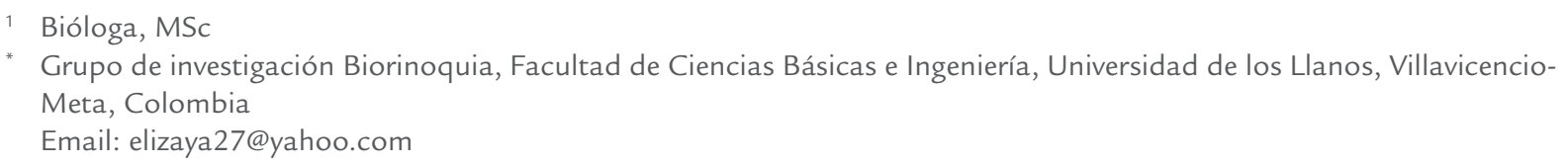

Recibido: septiembre 4 de $2012 \quad$ Aceptado: noviembre 29 de 2012

\begin{abstract}
Resumen
Macrobrachium amazonicum (Heller, 1862), es un camarón de la familia Palaemonidae. Vive en zonas litorales de ríos, caños y lagunas. En Colombia no se han realizado investigaciones en esta especie, por tal motivo el presente trabajo tiene como propósito estudiar la fecundidad y fertilidad para conocer sus ventajas como especie acuícola. Se monitorearon manualmente hembras ovígeras de M. amazonicum en la estación piscícola los guayabos ubicada en la vereda el medio del municipio de Restrepo-Meta con el fin de determinar su fecundidad y fertilidad. Para el estudio de la fecundidad se tuvo en cuenta el estadío de desarrollo II utilizado por Wehrtmann (1990),los huevos fueron retirados de los pleopodos con una pinza y colocados en solución Gilson, durante 10 días luego fueron contados manualmente. Para la determinación de la fertilidad se tuvo en cuenta la coloración de los huevos y el avanzado estado de desarrollo del embrión. Para los dos parámetros evaluados se registraron datos de longitud total $(\mathrm{mm})$ y peso $(\mathrm{g})$ de cada hembra. El valor máximo de fecundidad y fertilidad observado por hembra fue de 519 huevosy 458 larvas respectivamente; los cuales son muy bajos comparados con los reportados por Sampaio et al, 2004 que fueronde 2193 huevos y 2194 larvas. Aunque los resultados preliminares muestren estos valores por debajo de los encontrados por otros autores, esta especie presenta una ventaja como es, la de encontrársele en reproducción durante todo el año, lo cual podría compensar su baja fecundidad y fertilidad y hacerla viable para cultivo.
\end{abstract}

Palabras clave: Biología reproductiva, fecundidad, fertilidad, Macrobrachium amazonicum.

Key words: Reproductive aspects, reproductive biology, fecundity, fertility, Macrobrachium amazonicum 